\title{
Embryo Transfer in no Cycling Crioula and Quarter Horse Breeds Treated with Estradiol Cipionate and Long-acting Progesterone
}

\author{
Fernanda Kaercher ${ }^{1}$, Marlon Siqueira ${ }^{2}$, Alessandro Mercadante $^{2}$, Tatiana Figueiredo ${ }^{1}$, \\ Romildo Romualdo Weiss ${ }^{3}$, Felipe Siqueira ${ }^{2}$ and Luiz Ernandes Kozicki ${ }^{*}$ \\ ${ }^{I}$ Programa de Mestrado em Ciência Animal; Pontifícia Universidade Católica do Paraná; São José dos Pinhais - \\ $P R$ - Brasil. ${ }^{2}$ Central de Reprodução Eqüina; Tijucas do Sul - PR - Brasil. ${ }^{3}$ Departamento de Medicina \\ Veterinária; Universidade Federal do Paraná; Curitiba - PR - Brasil
}

\begin{abstract}
The aim of this work was to prepare the mares for embryo transfer. In group 1 (G1,treated, $n=15)$, recipient mares in anoestrus or in a transition period were treated with 5.0, 3.0 and $2.0 \mathrm{mg}$ of estradiol cipionate at the days 0,1 and 2 respectively, beginning at the day of ovulation $(D O)$. From the fourth day on, the mares this group received long-acting progesterone weekly, up to the 120 day of gestation. At D8, the embryo was collected from the donor and transferred to the recipient. At D12, the ultrasonographyc diagnosis of pregnancy was carried out. The control group (G2, not treated, $n=20$ ) was formed by cycling recipient mares, displaying ovulation at each 2 to 3 days after the donors mare ovulation. The pregnancy rate was higher $(p<0.05)$ in the mares from $G 2(85.0 \%)$ than from G1 $(53.3 \%)$. Thus, it could be concluded that the treated mares although showed lesser pregnancy rate than the cycling mare, were satisfactory alternative to be used mainly when there is no available cycling recipient.
\end{abstract}

Key words: Embryo transfer, Cycling and no cycling mares, Long acting progesterone, Estradiol cipionate, Mares recipient

\section{INTRODUCTION}

The embryo transfer (ET) in equine has become very intensive in use. However, there are searches to obtain better fertility rates. The embryo recipient mares constitute the critical point in a program of equine ET (Alonso, 2008). The estrus synchronization (ES), in regard to the embryonic implantation in recipient mares, is of fundamental importance. The utilization of mares in anoestrus as embryo recipient allows a more precocious beginning and a more late final of the equines ET programs since it is known that recipient mares reach the anoestrus step more early recommence the ovarian activity later than the donor mares (Testa et al., 2005).

The adequate selection of recipient mare and handling are also of fundamental importance in an ET program. An exemplary selection settles the quality of the recipient breeding stock, while an ideal handling furnishes the adequate environment to maximize the rate of pregnancy and the reduction of embryonic lost. Variables such as milk production, maternal skill, age, uterine and vulva condition must be considered for recipient selection (Alonso, 2008). Another important

*Author for correspondence: kozicki.1@pucpr.br 
characteristic to be considered is the age of animal (Carnevale et al., 2000; Stout, 2006), considering that the ideal age would be between 3 to 10 years (Squires and Seidel, 1995; Squires et al., 1999). According to Ricketts and Alonso (1991) and Morris and Allen (2002), the age is a very important predisposing factor for the endometrial degeneration, a condition that may compromise the maintenance of the gestation. Furthermore, the recipient's physical condition in regard to the donor and to the stallion (Stout, 2006) should also be considered.

There are several reports describing that the discrepancy between the genetic dimension of the embryo and the recipient mare affects the development intrauterine and the post-natal in different aspects. According to Allen et al. (2002), an inadequate maternal physical aspect causes either reduction or increase of the fetus. According to Squires et al. (1999), the ideal condition for a recipient mare is that one with procreated colts, a very important characteristic considering that in these animals the fertility evaluation is usually carried out by the number of products born per mare. In two ET programs carried out in Brazil (Rocha Filho et al., 2004; Testa et al., 2005), an evaluation has been conducted on the pregnancy index and on the precocious embryonic lost either in anoestrus or transitional no cycling recipient mares, which were treated with long-acting progesterone $\left(\mathrm{P}_{4}\right)$ weekly. Upon such treatments, however, no significant differences were observed between the no cycling and the cycling groups, anevidence showing that such treatment was trustful in regard to the gestation maintenance, allowing the attainment of fair rates of pregnancy after the ET. In the protocols followed by Rocha Filho et al. (2004) and Testa et al. (2005), the anoestrus mares were initially treated with estradiol cipionate (ECP) for three consecutive days, beginning the treatment with long-acting $\mathrm{P}_{4}$ one day after the ECP application and continuing weekly up to the 120 days of the recipient gestation.

It has to be considered that the ES between the donor and the recipient mares is of fundamental importance in the ET success. Oguri and Tsutsumi (1974) were unsuccessful in equine ET experiments using the recipient in which ovulation took place before the donors. On the other hand, Fleury et al. (2006) and Alonso (2007) did not find differences in the gestation rates in the recipient mares between the days minus 6 to 0 of asynchrony. The recipient selection at the day of ET performs direct influence on the pregnancy rate. For the success of this important methodology, a few aspects have to be considered, the most important ones being the day of the postovulation and the recipient uterine characteristics towards the palpation exam and to ultrasonography. According to Wisher et al. (2006), the synchrony between the embryo and the uterine environment is essential for the gestation settlement and development. Under the $\mathrm{P}_{4}$ mechanism of action the uterine environment undergoes a change. In an asynchronized uterus an embryo might be subjected to hormonal levels and growth factors not corresponding towards the actual biological phase in which it stands.

The employment of long-acting $\mathrm{P}_{4}$-treated no cycling mares in ET commercial programs is a routine in such activity. In this regard, some studies have been conducted aiming to find out the rates of early embryonic lost in the recipient subjected to such a protocol. Testa et al. (2005) performed the experiments in acyclic mares (protocol of three days of ECP and at the 4th day $1500 \mathrm{mg}$ of long-acting $\mathrm{P}_{4}$ ) evaluating the percentage of embryonic lost between the 15th and the 50th day of gestation. As hopeful results, it has been found that a total of $87 \%$ of mares maintained the gestation up to 50 days. Results showed that this protocol could be used.

The effect of intramuscular administration of oily $\mathrm{P}_{4}$ has been studied by Hughes et al. (1980) who showed that daily doses of 50 to $100 \mathrm{mg}$ were not sufficient to reach the blood plasma level that, according to Sharp (2000), was satisfactory towards the gestation maintenance, a level that could be attained by the administration of $200 \mathrm{mg}$ per day. This result confirmed that the serum levels of $\mathrm{P}_{4}$, lower than $1.0 \mathrm{ng} / \mathrm{mL}$, were characteristic of the estrus period. Heinrichs et al. (1987), by using an association of estradiol and progesterone, found out that there was suppression of the ovarian activity and that the recipient's uterine muscle tonus should be evaluated considering that it affected the pregnancy rates. Mares with excellent or good uterine tonus display best pregnancy rates than the mares with sufferable or poor tonus (Alonso, 2007).

The objective of the present work was to prepare the embryo recipient mares by the administration of a hormonal protocol based on ECP and intramuscular long-acting $\mathrm{P}_{4}$ formulation and compare the efficiency of such protocol in regard 
to cycling recipient mares in a program of equine ET.

\section{MATERIALS AND METHODS}

The study was carried out during July 2008 to February 2009. The embryo donors mares employed in the experiment belonged to Quarter Horse and Crioula breeds. They aged between 2 to 20 years and all of them had a body condition compatible with the reproductive activity. From the same breeding Center, 15 Quarter Horse and Crioula mares in anoestrus or in transition phase (G1 = Group 1- treated, $n=15$ ) with the absence of estrus and without follicles or with small follicles, (all of them useful as embryo recipient), were selected and treated with 5.0, 3.0 and $2.0 \mathrm{mg}$ of ECP (IM) at the days 0,1 and 2, respectively, with the beginning corresponding to the donator 0 day (D0 $=$ day of ovulation). From the $4^{\text {th }}$ day onwards, $200 \mathrm{mg}$ of oil $\mathrm{P}_{4}$ (IM) was administered to the recipient mares weekly up to the $120^{\text {th }}$ day of gestation. At the D8, the embryo was collected and a transcervical inovulation was carried out immediately for the recipient mare. At the D12, ultrasonographyc pregnancy diagnosis was carried out in 20 cycling recipient mares, forming Control Group G2 $(n=20)$. All the mares from this Group displayed natural ovulation two to three days after the donor ovulation. Otherwise, they were subjected to a daily control in regard to the ovulation without a previous hormonal treatment. Likewise in the G1, the embryos ovulation of the G2 was carried out following the same methodology, being similar the ultrasonographyc features of uterine tonus and ecogenicity at the touch in both groups of recipient animals. The rates of pregnancy and embryonic mortality were compared by the Qui-square test and the significance at the level of 5\%.

\section{RESULTS AND DISCUSSION}

According to Meira et al. (2008), both cycling and no cycling mares can be used as embryo recipient. This supports the desirability to consider the mares in anoestrus as embryo recipient as has been also reported by Mckinnon et al. (1988) and Carnevale et al. (2000). Furthermore, Rocha Filho et al. (2004) found that mares that did not ovulate and were in anoestrous or in the transitional phase, when treated with $\mathrm{P}_{4}$ of either short or long action before the embryonic inovulation. They could be successfully employed as embryo recipient and showed pregnancy rates in $\mathrm{P}_{4}$ treated cycling and no cycling mares of 75.0 and $75.9 \%$, respectively at the $12^{\text {th }}$ day of gestation. However, the present results showed discrepancy in regard to those achieved by Rocha Filho et al. (2004) not only in the difference between the pregnancy percentage that showed up to be higher (85\%) in the group of cycling mares, but also in the percentage (53.3\%) of no cycling mares. The result showed significant differences $(\mathrm{P}<0.05)$, which, however, was not found significant by Rocha Filho et al. (2004), for the rates of pregnancy and embryo mortality after the $12^{\text {th }}$ day of embryonic development (Table 1).

Table 1 - Percentage of pregnancy in cycling and no cycling (and treated) Crioula and Quarter Horse embryo recipient mares inovulated at the $8^{\text {th }}$ of the embryonic period. $2009(n=35)$.

\begin{tabular}{lcc}
\hline Ovulated Group & Pregnancy rate \% (n) & Embryo mortality \% (n) \\
\hline G1 (no cycling) & $53.3^{\mathrm{a}}(8 / 15)$ & $46.6^{\mathrm{a}}(7 / 15)$ \\
G2 (cycling) & $85.0^{\mathrm{b}}(17 / 20)$ & $15.0^{\mathrm{b}}(3 / 20)$ \\
\hline
\end{tabular}

According to Pessoa et al. (2005), the rates of pregnancy and the embryonic loss were not significantly different between the cycling and no cycling mares since an adequate dose of progesterone being administered until the synthesis of sufficient concentration of endogenous progesterone did occur (Mckinnon et al., 1988). A possibility for the reduced rates of pregnancy found in group G1 of this experiment might be a consequence of $\mathrm{P}_{4}$ low levels in the circulation due to the administration of only 200 $\mathrm{mg}$ of long-acting $\mathrm{P}_{4}$ at every 7 days, which was similar to those reported by Bringel et al.(2003) and Testa et al. (2005) that the circulating $\mathrm{P}_{4}$, as the mare maintaining gestation luteal activity, ought to be in levels of $1500 \mathrm{mg}$ at each 7 days, an index higher than that used in the present study. 


\section{CONCLUSION}

The results from the present study showed following conclusions:

- No cycling embryo recipient mares (in the anoestrous or in the transition period) can supply the deficiency of cycling embryo recipient mares mainly at the beginning of the breeding season, when only a few mares undergoing the cycling step were available.

- The ECP and the exogenous long-acting $\mathrm{P}_{4}$ protocol displayed a satisfactory alternative to be used in the programs of equine ET.

- It is advisable to use a minimum of $1500 \mathrm{mg}$ of $\mathrm{P}_{4}$ to no cycling or in transition period mares as weekly administration dose, aiming to increase the gestation rates.

\section{REFERENCES}

Allen, W.R., Wilsher, S., Turnbull, C., Stewart, F., Ousey, J., Rossdale, P.D., Fowden, A.L. 2002. Influence of maternal size on placental, fetal and postnatal growth in the horse. Anim. Reprod. Sci. 123, 445-453.

Alonso, M.A. 2007. Effect of uterine characteristics and day of cycle in pregnancy rates and progesterone concentration in candidate mares for embryo recipient. Master of Science Dissertation in Animal Science - State University Paulista. Botucatu, 2007.

Alonso, M.A. 2008. Selection, management and factors influencing pregnancy rate in recipient mare. Acta Sci. Vet. 36, 207-214.

Bringel, B.A., Jacob, J.C.F., Zimmerman, M., Alvarenga,M.A. Douglas, R.H. 2003. Biorelease progesterone LA 150 and its application to overcome effects of premature luteolysis on progesterone levels in mares. Rev. Bras. Reprod. Anim., 27,498-500.

Carnevale, E.M., Ramirez, R.J., Squires, E.L., Alvarenga, M.A., McCue, P.M. 2000. Factors affecting pregnancy rates and early embryonic death after equine embryo transfer. Theriogenology. 54, 965-979.

Fleury, P.D.C., Alonso, M.A., Balieiro, J.C.C. 2006. Evaluation of the recipient mare: Effect of uterine characteristics and time of ovulation. IN: XVIII Reunião Anual da Sociedade Brasileira de Tecnologia de Embriões, Araxá. Acta Sci. Vet., 34, 501.

Hinrichs, K., Sertich, P.L., Palmer, E., Kenney, M.R. 1987. Establishment and maintenance of pregnancy after embryo transfer in ovariectomized mares treated with progesterone. J. Reprod. Fert. 80, 395-401.
Hughes, J.P., Stabenfeldt, G.H., Kennedy, P.C.1980. The oestrus cycle and selected functional and pathologic ovarian abnormalities in the mare. Vet. Clin. North Amer. (Large Animal Practice),2, p.225239.

Meira, C., Ignácio, F.S., Ferreira, J.C., Montechiesi, D. F., Bicudo, S. D. 2008. State of the art in equine assisted reproduction. Acta Sci. Vet. 36, (supl. 2), 187-198.

Mckinnon, A.O., Squires, E.L., Carnevale, E.M., Hermenet, M.J. 1988. Ovariectomized steroid-treated mares as embryo transfer recipients and as a model to study the role of progestins in pregnancy maintenance, Theriogenology. 29, 1055-1063.

Morris, L.H., Allen, W.R. 2002. Reproductive efficiency of intensively managed thoroughbred mares in Newmarket. Eq. Vet. J. 34, 51-60.

Oguri, N., Tsutsumi, Y.1974. Non-surgical egg transfer in mares. J. Reprod. Fert. 41, 313-320.

Pessoa, M.A.,Rocha Filho, A.N., Carmo, M.T. 2005. Comparison between short and long acting progesterone for treatment of non cycling embryo recipient mares. IN: Proceedings of the International Symposium on Equine Embryo transfer, Havemeyer Foundation Monograph Series 14, Eds. M. Alvarenga and J.F.Wade, R \& W Publications, Newmarket, 8587.

Ricketts, S.W., Alonso, S.1991. The effect of age and parity on the development of equine chronic endometrial disease. Eq. Vet. J. 23,189-192.

Rocha Filho,A.N., Pessoa, M.A., Gioso,M.M., Alvarenga, M.A. 2004. Transfer of equine embryos into anovulatory recipients supplemented with short or long acting progesterone. Rev. Bras. Reprod. Anim. 27, 498-500.

Sharp,D.C. 2000 The early fetal life of the equine conceptus. Anim. Reprod. Sci. 60-61,6 79-689.

Squires, E.L., Seidel, G.E. 1995. Collection and transfer of equine embryos. Anim. Reprod. Biotech. Laboratory, Colorado State University, Bulletin 8.

Squires,E.L., McCue,P.M., Vanderwal,D.1999. The current status of equine embryo transfer. Theriogenology. 51, 91-104.

Stout, T.A.E. 2006. Equine embryo transfer: review of developing potential. Eq. Vet. J. 38, 467-478.

Testa,A.C., Carmo,M.T., Alvarenga, M.A. 2005. Early embryonic death in anovulatory recipients mares supplemented with long acting progesterone. Acta Sci. Vet. 33, 335.

Wilsher, S., Kolling, M., Allen, W.R. 2006. Meclofenamic acid extends donor-recipient asynchrony in equine embryo transfer. Eq. Vet. J., 38, 428-432.

Received: January 19, 2010; Revised: December 28, 2010; Accepted: July 01, 2011. 